\title{
Combined utilization of metabolic inhibitors to prevent synergistic multi-species biofilm formation
}

Dingrong Kang ${ }^{1 *} \mathbb{D}$, Wenzheng Liu ${ }^{1,2}$, Fatemeh Bajoul Kakahi ${ }^{1}$ and Frank Delvigne ${ }^{1 *}$

\begin{abstract}
Biofilm is ubiquitous in industrial water systems, causing biofouling and leading to heat transfer efficiency decreases. In particular, multi-species living in biofilms could boost biomass production and enhance treatment resistance. In this study, a total of 37 bacterial strains were isolated from a cooling tower biofilm where acetic acid and propionic acid were detected as the main carbon sources. These isolates mainly belonged to Proteobacteria and Firmicutes, which occupied more than $80 \%$ of the total strains according to the $16 \mathrm{~S}$ rRNA gene amplicon sequencing. Four species (Acinetobacter sp. CTS3, Corynebacterium sp. CTS5, Providencia sp. CTS12, and Pseudomonas sp. CTS17) were observed co-existing in the synthetic medium. Quantitative comparison of biofilm biomass from mono- and multispecies showed a synergistic effect towards biofilm formation among these four species. Three metabolic inhibitors (sulfathiazole, 3-bromopyruvic acid, and 3-nitropropionic acid) were employed to prevent biofilm formation based on their inhibitory effect on corresponding metabolic pathways. All of them displayed evident inhibition profiles to biofilm formation. Notably, combining these three inhibitors possessed a remarkable ability to block the multi-species biofilm development with lower concentrations, suggesting an enhanced effect appeared in simultaneous use. This study demonstrates that combined utilization of metabolic inhibitors is an alternative strategy to prevent multi-species biofilm formation.
\end{abstract}

\section{Key Points}

- 37 bacterial strains were isolated and identified from a cooling tower biofilm.

- Synergistic effect of biofilm formation was observed among four species.

- Three metabolic inhibitors showed effective inhibition against biofilm formation.

- Targeting cellular metabolism is an effective way to inhibit biofilm formation.

Keywords: Multi-species, Biofilm formation, Biofouling, Wastewater, Metabolic inhibitor

\footnotetext{
*Correspondence: dingrong.kang@hotmail.com; f.delvigne@uliege.be

1 TERRA Research and Teaching Centre, Microbial Processes and Interactions (MiPI), Gembloux Agro-Bio Tech, University of Liège, 5030 Gembloux, Belgium

Full list of author information is available at the end of the article
}

\section{Introduction}

Diverse microorganisms co-exist and form biofilms with emerging properties, such as enhanced nutrient acquisition, antibiotic tolerance, and internal cooperation in response to environmental stress (Elias and Banin 2012; Flemming et al. 2016; Karygianni et al. 2020). However, microbial biofilms can cause serious biofouling with concomitant efficiency reductions in industrial 
water systems, like cooling towers (Bott 1998). Water sources for cooling systems are commonly derived from groundwater or surface water (AM Peer and Sanders 2016). Recently, there is an increasing interest in using municipal or plant wastewater to replace freshwater consumption, because of environmentally beneficial and sustainable development (Li et al. 2011). Nevertheless, wastewater has abundant nutrient substances, such as volatile fatty acids (acetate, propionate, and butyrate). They are the essential intermediates in microbial fermentation processes, resulting in plentiful microbial growth and biofilm formation (Zhou et al. 2018). Therefore, seeking an effective strategy to reduce biofilm formation is crucial to prevent biofouling.

Microbial communities in cooling towers are highly dynamic, while they generally share taxa associated with biofilm formation (Tsao et al. 2019). A common core microbiome was identified from biofilms of four cooling towers filled with different water sources (Di Gregorio et al. 2017). In particular, Pseudomonas was acknowledged to be within the pioneer colonizers, following more species involved in forming multi-species biofilms (Doğruöz et al. 2009). Interspecific interactions including cross-feeding and metabolic exchange among mixed biofilms enhance biomass production, facilitate the microbes to survive in harsh environments, and increase resistance to external stress (Tan et al. 2017). Hence, targeting key species related to biofilm forming rather than free-living cells has been found effective to block biofouling.

Several approaches have been developed to limit biofilm formation in cooling water systems. The most frequent countermeasure is by adding biocides to target essential components, such as the cellular walls, membranes, structural proteins, and RNA/DNA (Di Pippo et al. 2018). However, microbes residing in biofilms display much higher tolerance to these biocides compared to free-living cells (Fux et al. 2005; Harrison et al. 2007). On the other hand, material modifications have shown their efficacy to prevent the initial biofilm attachment in the cooling pipes by coating with nanoparticles (Ogawa et al. 2016). Moreover, imidazolium and piperidiniumbased ionic liquids were found to inhibit cell adhesion to different materials, reducing biofilm formation (Anandkumar et al. 2020; Reddy et al. 2017). Other methods such as using the quorum quenching bacteria (Jo et al. 2016), ultrasonic treatments (Rodríguez-Calvo et al. 2020), and electromagnetic processes (Xiao et al. 2020) have been explored to obstruct biofilm development or eliminate the formed biofilms. Nevertheless, few of them are implemented with great success to field antifouling applications due to the limitations in terms of strain specificity, stability, and long-term efficacy (Flemming 2020).
Metabolic inhibitors are able to target specific microorganism pathways, acting on diverse gene expression regulative cascades and impacting metabolic functions (Mohiuddin et al. 2020; Saiardi et al. 2018). Different inhibitors were used against specific phenotypical traits like biofilm formation (Cho et al. 2020; Lohse et al. 2020). Regarding the latter, various metabolic pathways were reported to associate with biofilm development in recent years (Armbruster and Parsek 2018; Rabin et al. 2015). For instance, a previous study has illustrated that second messenger cyclic di-GMP (c-di-GMP) guides the bacterial switching behavior from a planktonic state to a biofilm formation lifestyle (Valentini and Filloux 2016). In this study, we investigated the efficacy of metabolic inhibitors on the multi-species biofilm formation from industrial water systems. Cultivable bacteria were isolated and identified, and synergistic biofilm communities were constructed from representative strains. Subsequently, three metabolic inhibitors: sulfathiazole (ST), 3-bromopyruvic acid (3BP), and 3-nitropropionic acid (3-NP) were employed to prevent the biofilm formation of multi-species. The present work is expected to provide an alternative strategy to overcome biofouling based on targeting cellular metabolism related to biofilm formation.

\section{Materials and methods \\ Biofilm sample and synthetic medium}

A biofilm sample was collected from a cooling tower located in a French industry plant that produces sugar and alcohol. The cooling tower was fed by wastewater with a $\mathrm{pH}$ range from 7.0 to $9.0\left(28^{\circ} \mathrm{C}\right)$. The main carbon sources found in wastewater were volatile fatty acids, including propionic acid $(1.50 \mathrm{~g} / \mathrm{L})$, acetic acid $(1.00 \mathrm{~g} / \mathrm{L})$, lactic acid $(0.016 \mathrm{~g} / \mathrm{L})$, and formic acid $(0.013 \mathrm{~g} / \mathrm{L})$. A synthetic medium was used to mimic the cooling tower environmental conditions. Synthetic medium was based on $\mathrm{M} 9$ minimal medium $\left(33.7 \mathrm{mM} \mathrm{Na} 2 \mathrm{HPO}_{4}, 22.0 \mathrm{mM}\right.$ $\mathrm{KH}_{2} \mathrm{PO}_{4}, 8.55 \mathrm{mM} \mathrm{NaCl} 9.35 \mathrm{mM} \mathrm{NH}_{4} \mathrm{Cl}, 1 \mathrm{mM} \mathrm{MgSO}$, $0.3 \mathrm{mM} \mathrm{CaCl}$, trace elements solution $(13.4 \mathrm{mM}$ EDTA, $3.1 \mathrm{mM} \mathrm{FeCl}{ }_{3}-6 \mathrm{H}_{2} \mathrm{O}, 0.62 \mathrm{mM} \mathrm{ZnCl}, 76 \mu \mathrm{M}$ $\mathrm{CuCl}_{2}-2 \mathrm{H}_{2} \mathrm{O}, 42 \mu \mathrm{M} \mathrm{CoCl}_{2}-2 \mathrm{H}_{2} \mathrm{O}, 162 \mu \mathrm{M} \mathrm{H}_{3} \mathrm{BO}_{3}, 8.1 \mu \mathrm{M}$ $\left.\mathrm{MnCl}_{2}-4 \mathrm{H}_{2} \mathrm{O}\right), 1 \mu \mathrm{g} / \mathrm{L}$ biotin and $1 \mu \mathrm{g} / \mathrm{L}$ thiamin), and supplemented with propionic acid $(1.50 \mathrm{~g} / \mathrm{L})$ and acetic acid $(1.00 \mathrm{~g} / \mathrm{L})$ as main carbon sources $(\mathrm{pH}=7.2)$.

\section{Strains isolation from biofilm sample}

A total of $10 \mathrm{~mL}$ biofilm sample (three biological replicates) was placed into a $50 \mathrm{~mL}$ centrifuge tube containing 15 sterile glass beads (diameter $2 \mathrm{~mm}$ ) and an equal volume of sterile phosphate-buffered saline solution (PBS). The sample was then homogenized using a vortex mixer for $30 \mathrm{~s}$ at $2500 \mathrm{rpm}$ and serially diluted to $1 \times 10^{-7}$ with PBS. A $100 \mu \mathrm{L}$ aliquot of each serial dilution was spread 
onto LB agar plates in triplicate because the standard wastewater medium is not available. LB is a common medium that can provide the nutrient to a majority of representative strains for cell growth. Certainly, some strains may prefer to grow in the wastewater and not with the LB medium, which were not considered in this study. Agar plates were incubated at $30^{\circ} \mathrm{C}$ for two to five days. Colonies were selected by differentiable morphologies.

\section{Identification of isolated strains}

Obtained strains were grown in fresh LB medium overnight and spread on LB plates three times to ensure pure cultures. Two-milliliter suspension of each pure culture was used for DNA extraction. DNA was extracted by using Genejet Genomic DNA Purification Kit according to the manufacturer's instructions. Following DNA was used as a template to amplify and sequence the full $16 \mathrm{~S}$ rRNA gene with primers (8F 5' - AGAGTTTGATCCTGGCTC AG - 3'; 1492R 5' - ACGGTTACCTTGTTACGACTT $\left.-3^{\prime}\right)$ by the Sanger method. Full sequences were checked and jointed manually using 4Peaks software (https://nucle obytes.com/4peaks/index.html). Resulting 16S rRNA gene sequences were queried and identified with reference sequences in the Silva database.

\section{Constructing the phylogenetic trees of isolated strains}

For constructing the phylogenetic tree of these isolates, obtained 16S rRNA gene sequences were aligned and processed by MEGAX software (Kumar et al. 2018). The evolutionary relationship was inferred by using the Maximum Likelihood method and the Tamura-Nei model. To uncover the phylogenetic evolution relationship of single strains within the genera, reference sequences were downloaded from the NCBI database and aligned with the resulting sequences. The phylogenetic trees of single strains were constructed as described above.

\section{Screening multi-species biofilm formation by using crystal violet (CV) assay}

Ten representative strains from four phyla were selected for the co-existence assay, which was performed with ten successive cycles of repeated batch cultivation. The purpose of this assay was to further screen multi-species with potential synergy to form biofilm. Obtained four strains grown as single- and multi-species by using a Nunc-TSP lid culture system, which comprises a 96-well plate lid with pegs extending into each well. Pre-cultures were grown up to $\mathrm{OD}_{600 \mathrm{~nm}} 1.0$ at $30^{\circ} \mathrm{C}$. The cell suspensions were then adjusted to $10^{8}$ cells per milliliter in the synthetic medium. A total of $160 \mu \mathrm{L}$ monoculture or mixed cultures (equal volume for each) were added to each well. Fresh medium was used as the negative control. The plates were sealed with Parafilm and incubated with shaking $200 \mathrm{rpm}$ at $30{ }^{\circ} \mathrm{C}$. Biofilm formation was quantified by crystal violet (CV) staining after 24 and $48 \mathrm{~h}$ of cultivation, as previously reported $\mathrm{CV}$ assays (Ren et al. 2014). CV quantification was performed on the pegs of the Nunc-TSP lid culture system. The peg lids were taken out and washed three times using PBS. Subsequently, the peg lids were placed in plates with 180 $\mu \mathrm{L}$ of an aqueous $1 \%(\mathrm{w} / \mathrm{v}) \mathrm{CV}$ solution. The lids were rewashed three times with PBS after staining for $20 \mathrm{~min}$. Peg lids were put into a new microtiter plate with $200 \mu \mathrm{L}$ of $33 \%$ glacial acetic acid. After $15 \mathrm{~min}$, the dissolved CV solution's absorbance was determined at $590 \mathrm{~nm}$ using a microplate reader (Tecan, Spark).

\section{Inhibition assay of cell proliferation}

The cell suspensions were adjusted to $10^{8}$ cells per milliliter in the synthetic medium. A total of $200 \mu \mathrm{L}$ monoculture or mixed cultures (equal volume for each) were added to each well of 96-well plates. Different final concentrations of metabolic inhibitors (ST, 3BP, and 3-NP) were supplied to the bacterial suspension from $2 \mu \mathrm{g} / \mathrm{mL}$ to $256 \mu \mathrm{g} / \mathrm{mL}$. No treatment was used as a control. Then the plate with cultures was placed on the shaker using $200 \mathrm{rpm}$ at $30{ }^{\circ} \mathrm{C}$. Cell proliferation was measured based on the net increase of the $\mathrm{OD}_{600 \mathrm{~nm}}$ value using a microplate reader (Tecan, Spark) after 24 and $48 \mathrm{~h}$.

\section{Inhibition assay of biofilm formation}

A total of $160 \mu \mathrm{L}$ bacterial suspension $\left(1 \times 10^{8}\right.$ cells $\left./ \mathrm{mL}\right)$ in terms of monoculture and mixed cultures were prepared as above, then added to the Nunc-TSP lid culture system. Following metabolic inhibitors and their combinations were supplied to the suspension with different concentrations from 2 to $256 \mu \mathrm{g} / \mathrm{mL}$, and no inhibitor addition was as the control. The plates were then placed on the shaker at $200 \mathrm{rpm}$ and $30{ }^{\circ} \mathrm{C}$. The biofilm quantification assays were performed as described above. The $\mathrm{CV}$ absorbance at $590 \mathrm{~nm}$ was used to evaluate the inhibiting effect on biofilm formation.

\section{Statistical analysis}

All experiments were performed at least with four biological replicates in this study. One-way ANOVA followed by post hoc Tukey's HSD tests were used for establishing the statistical differences of biofilm-forming capabilities. The significance level was set to $p<0.05$.

\section{Results}

\section{Isolation and identification of strains from biofilm}

The viable strains that displayed distinct morphological features were isolated and identified from the cooling tower biofilm sample. Thirty-seven strains were found to belong to four phyla: Actinobacteria, Proteobacteria, 
Bacteroidetes, and Firmicutes (Fig. 1). Twenty strains were identified as Proteobacteria, consisting of nine genera, of which Pseudomonas was the most extensive branch. To further obtain a simplified microbial community with the capacity to use volatile fatty acids collectively, ten representative strains from the four phyla were selected to co-culture in a continuous mode. A total of four species, including Acinetobacter sp. CTS3 (A3), Corynebacterium sp. CTS5 (C5), Providencia sp. CTS12 (P12), and Pseudomonas sp. CTS17 (P17) were verified to be a stable coexistence over time. Phylogenic trees of each strain were constructed to explore the evolutionary relationship within the genus (Additional file 1: Fig. S1-S4). The result shows that the closest evolutionary relationship of A3 is Acinetobacter johnsonii (Additional file 1: Fig. S1). Similarly, Pseudomonas composti was found to be the closest related species with P17 (Additional file 1: Fig. S4). For C5 and P12, the closest references are Corynebacterium glutamicum and Providencia heimbachae, respectively (Additional file 1: Figs. S2 and S3).

\section{Obtaining of multi-species biofilms with synergistic interaction}

To obtain the multi-species biofilms and characterize their possible synergetic effect, all potential combinations of the four strains (single, dual-, triple-, and quadruple species) were cultured in the synthetic medium (Fig. 2a, b). Suspended cell density and biofilm-forming capacity were measured after 24 and $48 \mathrm{~h}$. Four strains were found with different cell densities $\left(\mathrm{OD}_{600 \mathrm{~nm}}\right)$ after the cultivation, suggesting that they can grow independently but exhibit different capacities to assimilate the volatile fatty acids. For all mixture cultivations, the A3P17 pair was presented with the highest cell density $\left(\mathrm{OD}_{600 \mathrm{~nm}}: 0.65\right)$ after $24 \mathrm{~h}$. The other mixtures' cell density range was between 0.24 and 0.63 after $24 \mathrm{~h}$. A3, C5,

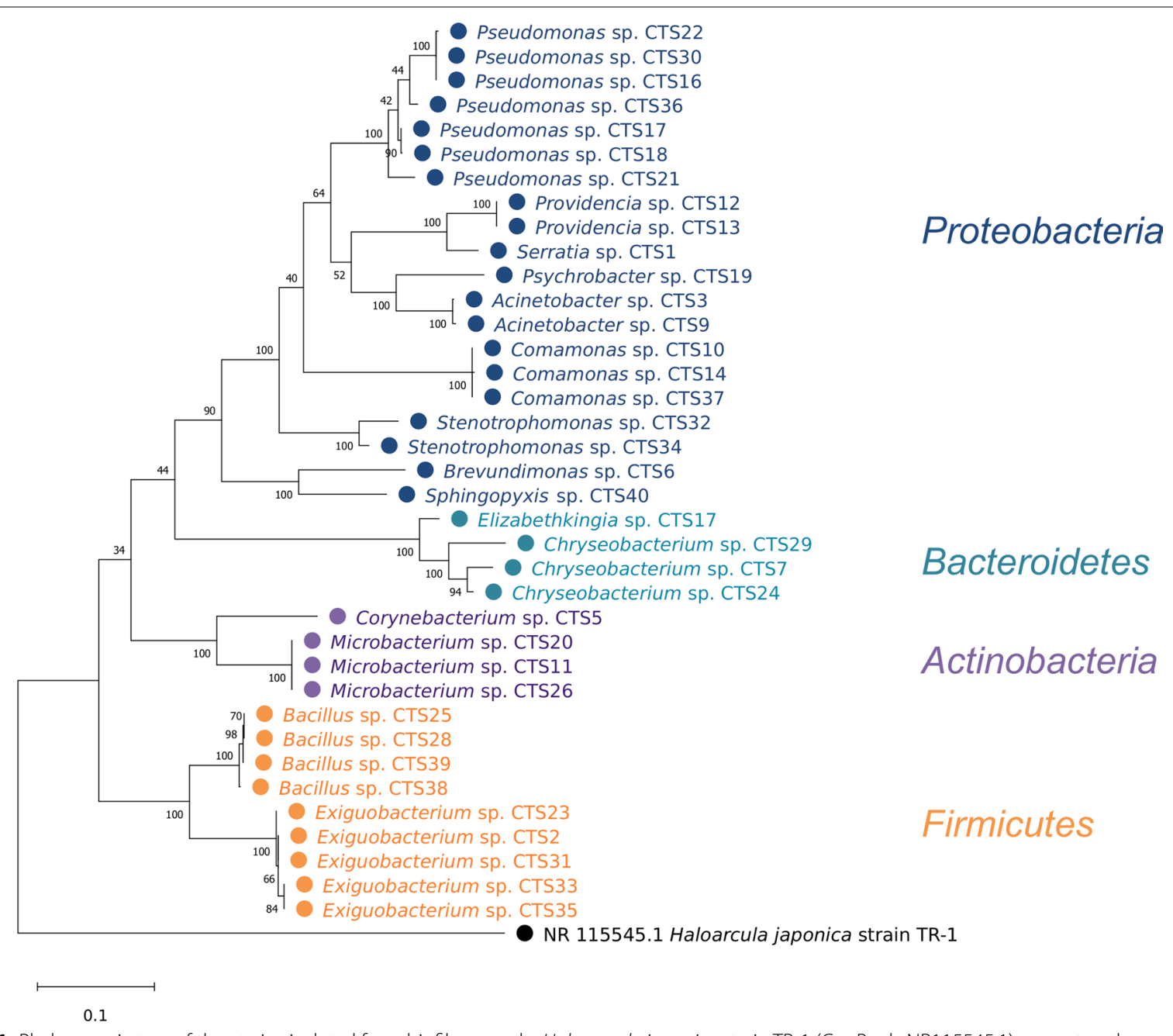

Fig. 1 Phylogenetic tree of the strains isolated from biofilm sample. Halocarcula japonica strain TR-1 (GenBank: NR115545.1) was set as the outgroup species. Bootstrap values are displayed at each node 

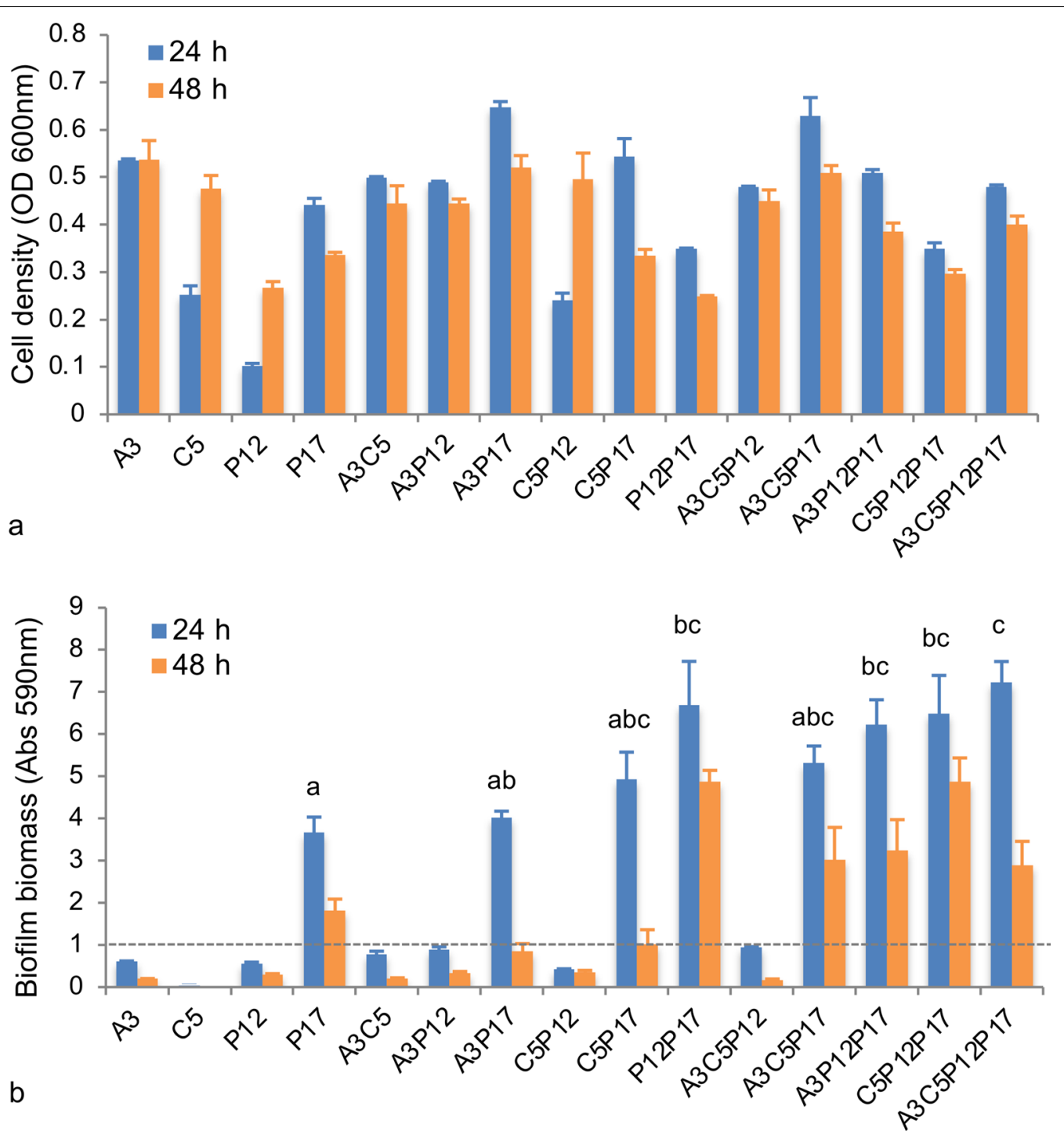

Fig. 2 Comparison of cell density and biofilm biomass from mono- and multi-species cultures after 24 and $48 \mathrm{~h}$. a Measurement of cell density. b Measurement of biofilm biomass. A3: Acinetobacter sp. CTS3, C5: Corynebacterium sp. CTS5, P12: Providencia sp. CTS12, and P17: Pseudomonas sp. CTS17. Lowercases mean significant differences of biofilm-forming capacity (above 1.0 (CV value)) among the cultures after $24 \mathrm{~h}$, showing by different letters based on one-way ANOVA using post-hoc Tukey's HSD test $(p<0.05)$. The detailed $p$ values could be found in the Table S1

and P12 cultures showed a low capacity to form biofilm, with $\mathrm{CV}$ values $\left(\mathrm{Abs}_{590 \mathrm{~nm}}\right)$ below 0.25 . In contrast, the CV value from P17 culture showed a higher than 10-fold increase displaying a strong capacity for biofilm production. It is worth noting that all of the bacterial combinations comprising P17 possessed a strong ability to form a biofilm. The latter was predominantly observed in the four-species community. The CV value reached up to 8.30 after $24 \mathrm{~h}$, suggesting an evident synergistic effect on biofilm formation among these species.
Inhibitory effect of ST, 3BP, and 3-NP on cell proliferation

Three chemical agents, i.e., sulfathiazole (ST), 3-bromopyruvic acid (3BP), and 3-nitropropionic acid (3-NP), were applied as the metabolic inhibitors to act on the cell proliferation of mono- and multi-species (four species). Cell density after 24 and $48 \mathrm{~h}$ cultivation was recorded with the treatment of different concentrations (Fig. 3). Three agents displayed different inhibitory effects on cell proliferation among four mono-species. ST cannot inhibit any of them entirely below the concentration of $256 \mu \mathrm{g} / \mathrm{mL}$, but it showed a visible inhibiting effect 
$24 \mathrm{~h}$

ST

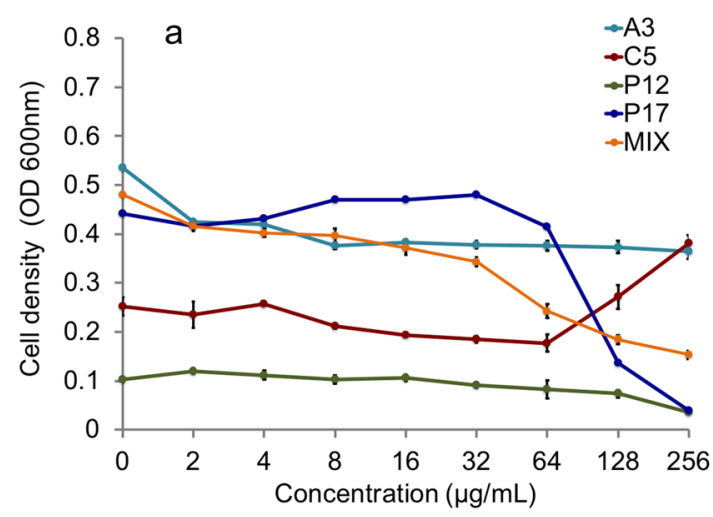

3BP

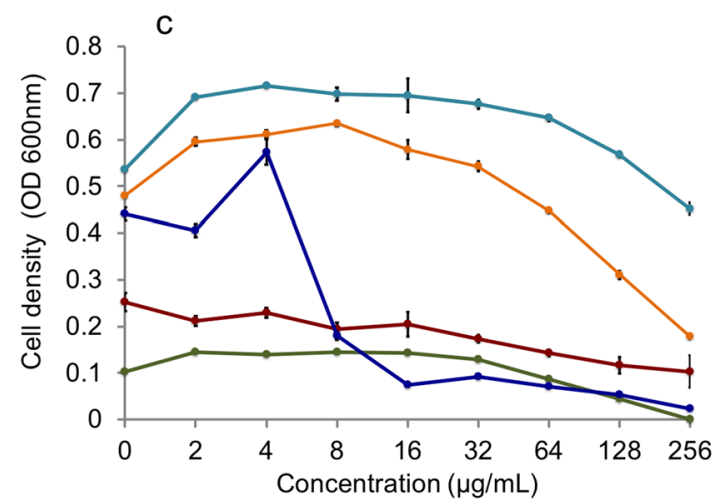

3-NP

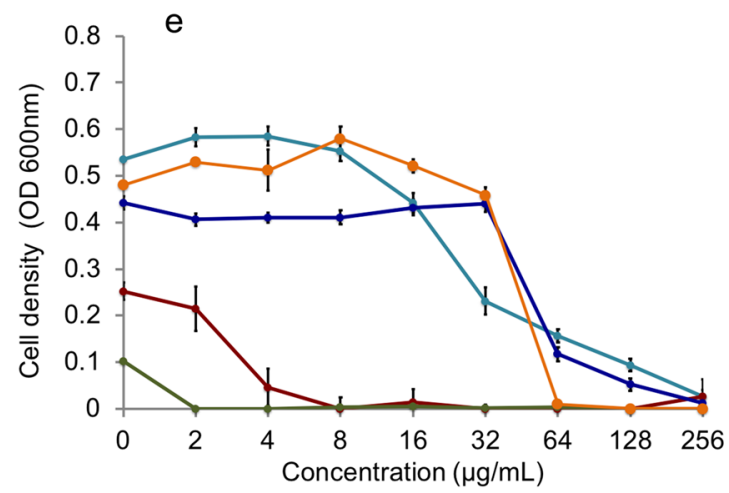

$48 \mathrm{~h}$
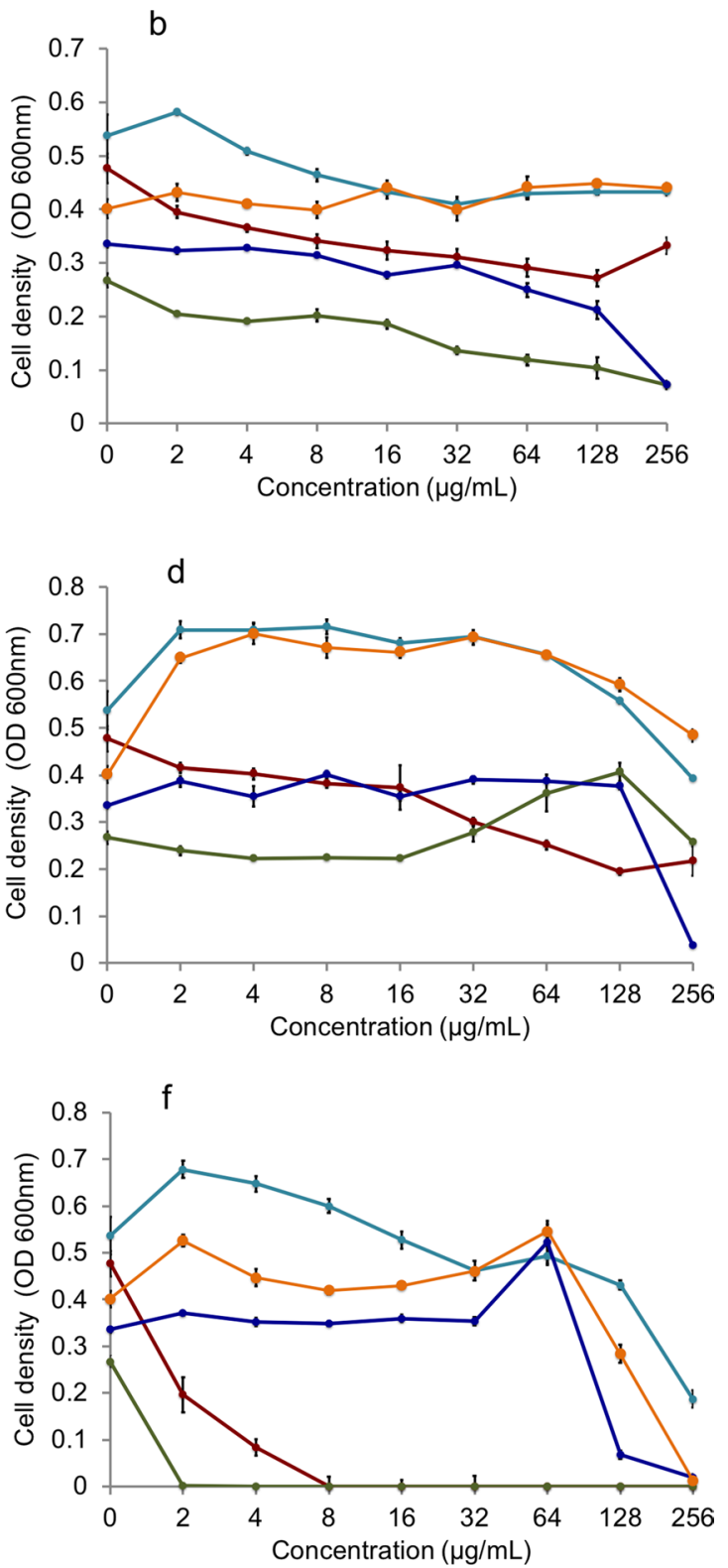

Fig. 3 Cell density of monoculture (A3, C5, P12, and P17) and four species (MIX) culture with different metabolic inhibitors after 24 and $48 \mathrm{~h}$. a Measurement of cell density with gradient concentrations of ST (sulfathiazole) ( $24 \mathrm{~h}$ ). b Measurement of cell density with gradient concentrations of ST (48 h). c Measurement of cell density with gradient concentrations of 3BP (3-bromopyruvic acid) (24h). $\mathbf{d}$ Measurement of cell density with gradient concentrations of 3BP (48h). e Measurement of cell density with gradient concentrations of 3-NP (3-nitropropionic acid) (24h). $\mathbf{f}$ Measurement of cell density with gradient concentrations of 3-NP (48h). $n=4$

to P17, especially as the concentration above $64 \mu \mathrm{g} / \mathrm{mL}$ (Fig. 3a, b). 3BP was able to prevent the cell proliferation of P12 and P17 almost entirely after $24 \mathrm{~h}$ with a concentration of $256 \mu \mathrm{g} / \mathrm{mL}$, following the inhibiting effect was still acting on P17, but not P12 after 48 h (Fig. 3c, d). Notably, 3-NP presented a more substantial inhibitory effect than the other two (ST, 3BP) on these species (Fig. 3e, f). The cell proliferation of $\mathrm{C} 5$ and P12 was inhibited completely with concentrations of $2 \mu \mathrm{g} / \mathrm{mL}$ and $8 \mu \mathrm{g} / \mathrm{mL}$, respectively. Additionally, cell proliferation of multi-species showed a distinct performance with three metabolic inhibitors. Cell density was reduced along with 
increasing concentrations of ST and 3BP after $24 \mathrm{~h}$, while it was not affected even higher than the control after $48 \mathrm{~h}$. Nevertheless, 3-NP still displayed an effective inhibition to the multi-species in $24 \mathrm{~h}(64 \mu \mathrm{g} / \mathrm{mL})$ and $48 \mathrm{~h}(256 \mu \mathrm{g} /$ $\mathrm{mL}$ ), which was able to inhibit them fully.

\section{Inhibitory effect of ST, 3BP, and 3-NP on biofilm formation}

Serial concentrations of ST, 3BP, and 3-NP were added to P17 and multi-species (four species) cultures to evaluate their inhibitory effect on biofilm formation (Fig. 4). Three inhibitors displayed different inhibition patterns on the biofilm forming capacity of P17. This inhibitory effect was proved to increase along with increasing inhibitor concentrations, from $64 \mu \mathrm{g} / \mathrm{mL}$ up to $256 \mu \mathrm{g} / \mathrm{mL}$. On the other hand, low inhibitor concentrations seem to boost biofilm formation, especially with 3BP. Notably, more than $95 \%$ reduction on biofilm formation was achieved with $3 B P$ after $24 \mathrm{~h}$ at a concentration of $16 \mu \mathrm{g} / \mathrm{mL}$ and after $48 \mathrm{~h}$ at a concentration of $32 \mu \mathrm{g} / \mathrm{mL}$. 3-NP and ST also were able to inhibit the biofilm formation effectively within concentrations of $64 \mu \mathrm{g} / \mathrm{mL}$ and $128 \mu \mathrm{g} / \mathrm{mL}$. Moreover, these inhibitors displayed an inhibitory effect on multi-species growth. 3-NP showed the highest inhibitory capacity even at low concentrations of $2 \mu \mathrm{g} / \mathrm{mL}$ after $24 \mathrm{~h}$, while biofilm was formed after $48 \mathrm{~h}$. Similarly, multispecies biofilms were enhanced with other two inhibitors after $48 \mathrm{~h}$ compared to the biofilm quantification at $24 \mathrm{~h}$. Despite the latter, biofilm formation was almost inhibited after 24 and $48 \mathrm{~h}$ when the inhibitor concentration reached $256 \mu \mathrm{g} / \mathrm{mL}$.

\section{Enhancement of inhibitory effect on biofilm formation via combined inhibitors}

Additionally, combinations of ST, 3BP, and 3-NP were used against the mono- and multi-species to investigate the enhancement effect. Inhibitor combinations showed a remarkable inhibitory effect on biofilm formation in P17 and multi-species (four species) cultures (Fig. 5).

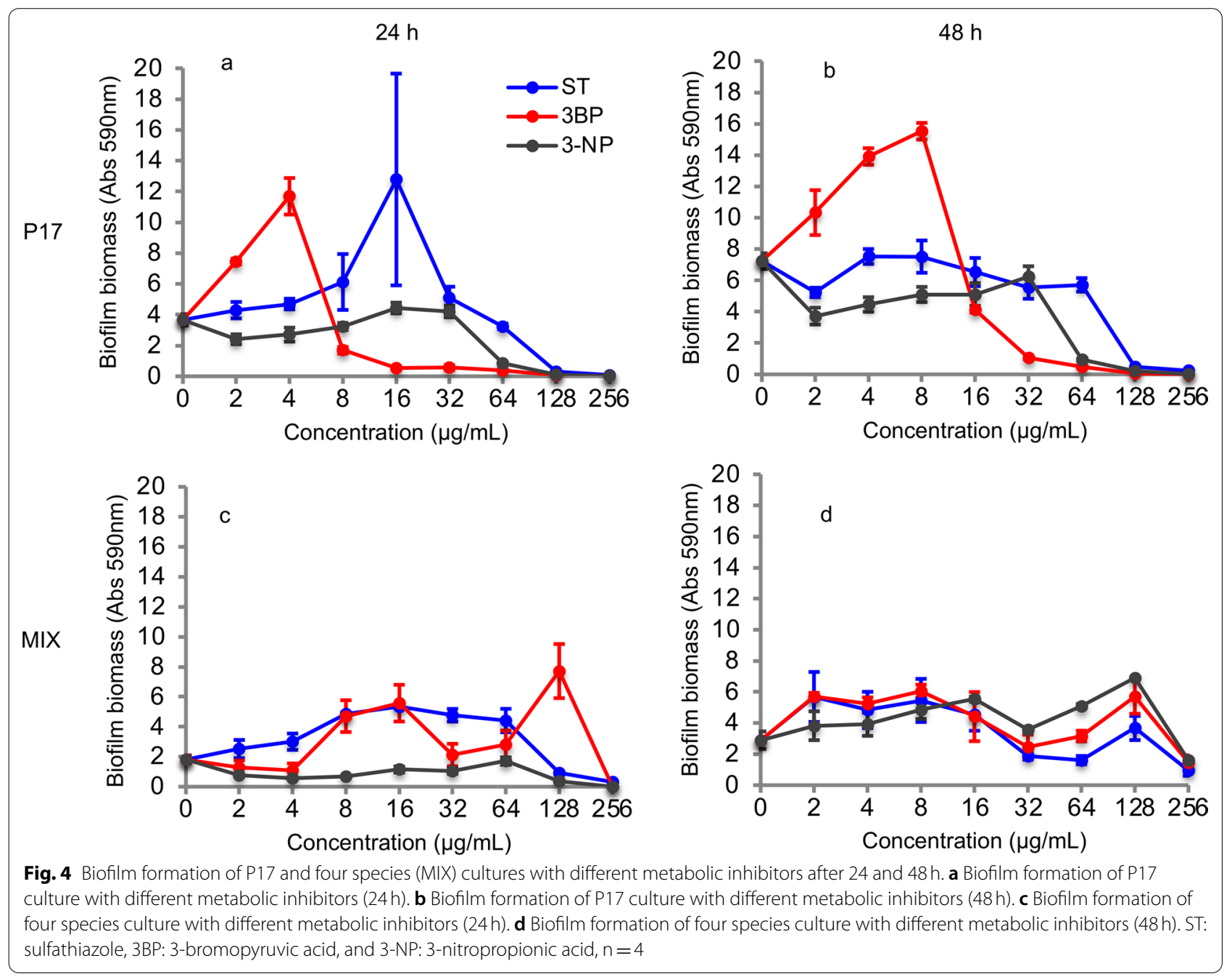




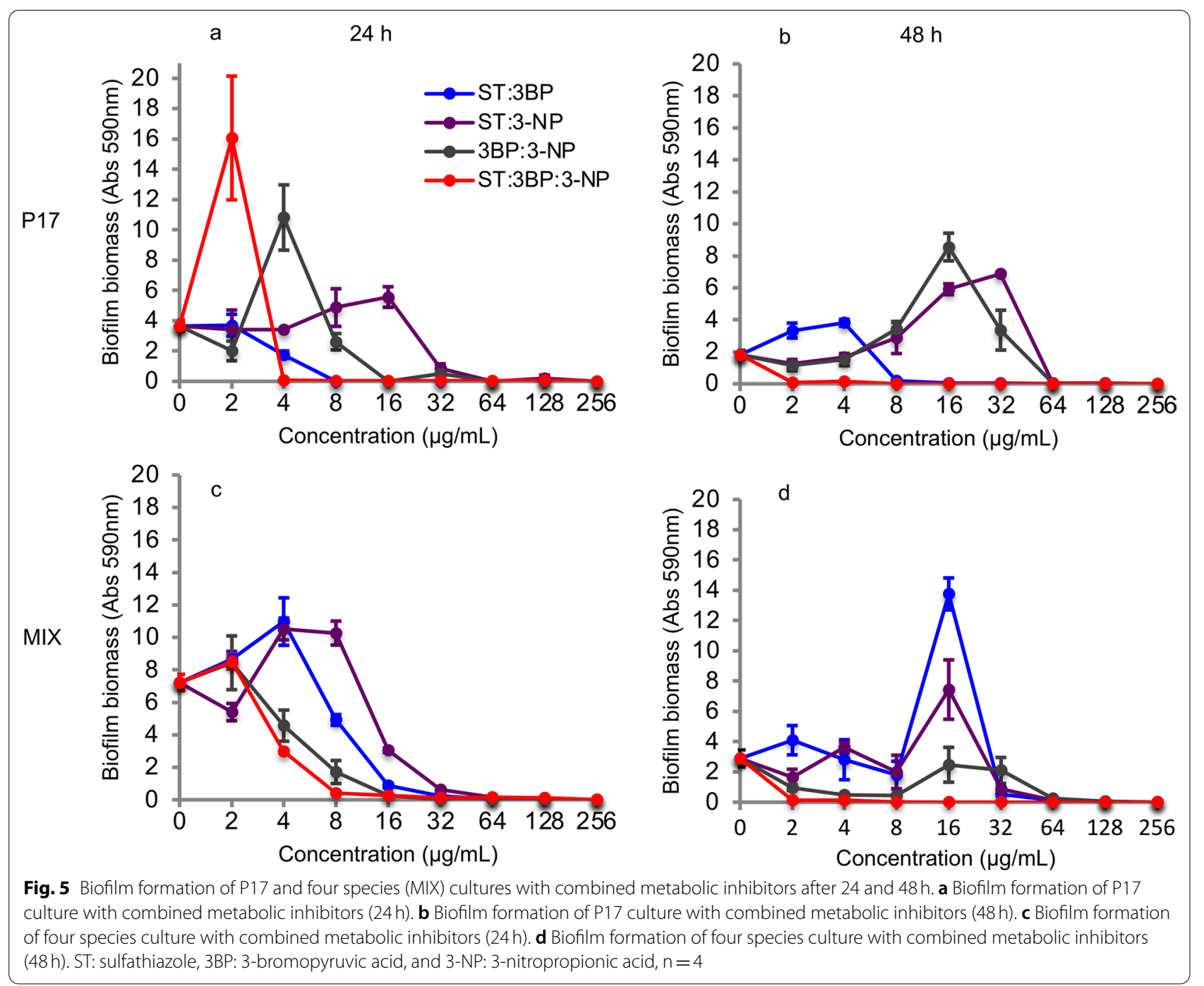

Dual inhibitors combination (ST and 3BP) inhibited P17 biofilm formation almost wholly at a concentration of $8 \mu \mathrm{g} / \mathrm{mL}$ within $48 \mathrm{~h}$. These results show a remarkably higher inhibitory effect from simultaneous utilization of $\mathrm{ST}$ and 3BP compared to their independent usage (ST: $128 \mu \mathrm{g} / \mathrm{mL}, 3 B P: 64 \mu \mathrm{g} / \mathrm{mL}$ ). Similarly, the other dualinhibitor combinations (ST:3-NP and 3BP:3-NP) also presented strong inhibitory effects on biofilm formation. They were able to inhibit the biofilm-forming of P17 and multi-species entirely with a concentration of $64 \mu \mathrm{g} / \mathrm{mL}$ after 24 and $48 \mathrm{~h}$, of which the concentration was found to be lower than their individual usage. Notably, the combination of three inhibitors displayed an extreme inhibitory efficiency, which stopped the biofilm-forming of P17 and multi-species completely by treating with concentrations as low as $4 \mu \mathrm{g} / \mathrm{mL}$ and $8 \mu \mathrm{g} / \mathrm{mL}$, respectively. Only low biofilm formation was detected even after $96 \mathrm{~h}$; it showed that the combined inhibitors were able to impact the biofilm-forming persistently (Additional file 1: Figure S5). These results demonstrate that an enhancement effect exists among the inhibitors, especially for combining three of them. The latter and their inhibition characterization make it clear that they could be part of a promising regulated strategy to prevent biofilm formation of mono- and multi-species.

\section{Discussion}

In this study, cultivable bacterial isolates were identified from a biofilm sample originating from a cooling tower. The capacity of biofilm formation among representative species was evaluated, showing the synergistic effect of biofilm formation among four species. Three metabolic inhibitors (ST, 3BP, and 3-NP) were selected against cell proliferation and biofilm formation owing to their ability to target vital metabolic pathways in cellular metabolism. They displayed distinct inhibitory effects on cell 
proliferation, and all of them could inhibit the biofilm development with concentrations lower than $256 \mu \mathrm{g} /$ $\mathrm{mL}$. Notably, combining three inhibitors possessed potent inhibition with a much low concentration $(8 \mu \mathrm{g} /$ $\mathrm{mL}$ ) against the mono- and multi-species biofilms for a long time. Targeting cellular metabolism with distinct functional metabolic inhibitors turns into a promising approach to prevent multi-species biofilm formation.

Many studies have reported the microbial composition from cooling water systems. A combined NGS-based approach was used to study the whole bacterial community from a cooling tower, which displayed a highly diverse bacterial community with more than 808 genera observed (Pereira et al. 2017). Seven species producing extracellular polymeric substances were isolated and characterized from the cooling tower through sequential culturing in an enriched medium (Ceyhan and Ozdemir 2008). 37 bacterial strains were identified in the cooling water biofilm mainly belonging to Proteobacteria and Firmicutes, which occupied more than $80 \%$ of the total isolates in this study. Proteobacteria has been identified as the predominant bacteria in biofilms growing on recirculating cooling-water systems (MacDonald and Brözel 2000; Pinel et al. 2020). Firmicutes and Proteobacteria were described as the most dominant phyla in the ecosystems of cooling towers within sugar-cane processing plants (Sharmin et al. 2013). In fact, most of the identified strains such as Pseudomonas sp., Acinetobacter sp., Corynebacterium sp. have been detected from various wastewater environments (Greay et al. 2019; Han et al. 2020). Besides, Providencia sp. was isolated from wastewater and applied to perform microbial remediation (Abo-Amer et al. 2013). A frequent species, Legionella, was not detected, while Legionella was frequently observed in biofilms obtained from cooling water suspensions (Edagawa et al. 2008; Pereira et al. 2017). A previous study uncovered that Pseudomonas species had a robust negative correlation with Legionella in cooling towers (Paranjape et al. 2020), which may explain the lack of Legionella in the present microbial community. Overall, these isolates are likely to have social interaction related to biofilm formation, as they are living in such an environment.

Building a multi-species biofilm model has more ecological relevance compared to mono-culture model, which serves as an effective way to explore biofilm development in natural conditions (Røder et al. 2016). A high prevalence of synergistic effects was observed from different isolates during biofilm development (Liu et al. 2019; Ren et al. 2015). In the present work, four species were able to assimilate and tolerate the supplied volatile fatty acids in the synthetic medium. In fact, volatile fatty acids can also inhibit cell growth or display distinctive toxic effects (Pinhal et al. 2019; Wilbanks and Trinh 2017). Except for their growth capabilities, P17 was found to form biofilm when cultured alone. Pseudomonas species are frequent inhabitants in freshwater environments via adhesion and biofilm formation (Pereira et al. 2018). The result confirms the vital role of Pseudomonas species during the biofilm forming process in the cooling tower. Intriguingly, biofilm biomass of the dual-/ tripleand four species was promoted when P17 was present, showing a synergistic effect between these biofilm production strains. Previous studies have demonstrated that Pseudomonas had diverse molecular interactions with Acinetobacter sp. (Hansen et al. 2007) and Corynebacterium sp. (Brathwaite and Dickey 1970). Nevertheless, synergic mechanisms among the four species are still not clear, further exploration is needed to reveal the synergy for biofilm formation.

Recently, plentiful small-molecule agents have been developed to treat microbial biofilms based on their mechanistic understanding (Qvortrup et al. 2019). In this study, three metabolic inhibitors were selected as they can target distinct metabolic pathways. ST was found with the broadest activity spectrum against microbial biofilms, which has been selected to prevent multi-species biofilm formation (Parijs and Steenackers 2018). It has been reported to interfere with c-di-GMP biosynthesis, thereby reducing biofilm formation effectively (Antoniani et al. 2010). c-di-GMP is used as a signaling system with a crucial role in regulating bacterial behavior and especially for biofilm formation (Jenal et al. 2017). Therefore, the potential mechanism that ST prevents biofilm formation could be inhibiting c-di-GMP biosynthesis (Fig. 4). 3BP and 3-NP also displayed the visible inhibiting effect to the biofilm formation (Fig. 4). Previous studies showed that 3BP and 3-NP were the enzyme inhibitors to succinate dehydrogenase and isocitrate lyase, which are essential enzymes from metabolic pathways of volatile fatty acids catabolism (Moynihan and Murkin 2014; Sharma et al. 2000). Furthermore, 3BP has been described as a potent inhibitor to glycolysis/gluconeogenesis (Darabedian et al. 2018), which is related to converting the intermediates from volatile fatty acids catabolism to biofilm precursors (monosaccharides, eDNA). These could be the reasons that 3BP and 3-NP are able to prevent cell growth and biofilm formation. Particularly, the inhibitory efficiency to biofilm development was remarkably improved when using three metabolic inhibitors simultaneously, implying that they targeted different metabolic pathways related to biofilm forming.

Unexpectedly, the biofilm formation of P17 and multi-species were promoted under relatively low concentration of the metabolic inhibitors, for instance, treating P17 with ST $(16 \mu \mathrm{g} / \mathrm{mL})$ after $24 \mathrm{~h}$ (Fig. 4a), 
treating multi-species with ST:3BP $(16 \mu \mathrm{g} / \mathrm{mL})$ after $48 \mathrm{~h}$ (Fig. 5d). In fact, some antibiotic's subinhibitory concentrations have been found to promote microbial biofilm formation by a trade-off between drug toxicity and the beneficial results of cell lysis (Yu et al. 2018). It suggests that the trade-off of inhibitor effect and beneficial factors is present when using metabolic inhibitors to prevent biofilm formation. Further inquiry into the interplay between bacterial response and inhibitor efficacy in biofilm development is necessary to determine each inhibitor's optimal conditions. Our results indicated that combined the three metabolic inhibitors prevented the biofilm formation for more than $96 \mathrm{~h}$ (Figure S5). In fact, many metabolic inhibitors can be degraded by particular microorganisms; for instance, Phanerochaete chrysosporium is capable of removing ST (Kwak et al. 2017). Further investigation of their degradation rates and stability is necessary to ensure long-term efficacy.

Overall, we isolated the biofilm-forming related microorganisms and developed a multi-species biofilm model by mimicking a natural cooling water system. Culturing results showed that four species were able to assimilate the volatile fatty acids and generate biofilm biomass with a synergistic effect. Combined metabolic inhibitors displayed an effective inhibitory effect on biofilm development, which demonstrated that targeting cellular metabolism is a potent approach to inhibit synergistic biofilm formation of multi-species. Exploring the bacterial responses to these metabolic inhibitors and building more complex biofilm systems will help evaluate their inhibiting efficacy in practice.

\section{Abbreviations}

ST: Sulfathiazole; 3BP: 3-bromopyruvic acid; 3-NP: 3-nitropropionic acid; c-di-GMP: Cyclic di-GMP; LB: Lysogeny broth; CV: Crystal violet; A3: Acinetobacter sp. CTS3; C5: Corynebacterium sp. CTS5; P12: Providencia sp. CTS12; P17: Pseudomonas sp. CTS17.

\section{Supplementary Information}

The online version contains supplementary material available at https://doi. org/10.1186/s13568-022-01363-4.

Additional file 1. Additional figures.

\section{Acknowledgements}

The authors would like to acknowledge Juan Andres Martinez for the language editing and proofreading.

\section{Preprint}

Kang, D., Liu, W., Kakahi, F. B., \& Delvigne, F. (2021). Targeting cellular metabolism to inhibit synergistic biofilm formation of multi-species isolated from a cooling water system. bioRxiv. Available at: https://www.biorxiv.org/ content/https://doi.org/10.1101/2021.01.28.428600v1.

\section{Authors' contributions}

FD and DK contributed to the conception of this study. DK, WL, and FD contributed to the development of the research plan and experimental investigation. DK conducted all the data analyses and wrote the first draft of the manuscript. WL, FBK, and FD contributed to revising the manuscript. All authors read and approved the final manuscript.

\section{Funding}

This study was supported by Talk2Clean project through the funding from Walloon Region (Grant Number: 7988).

\section{Availability of data and materials}

Sequencing data are available at the NCBI GenBank database with the accession numbers MW389057 - MW389093, including Acinetobacter sp. CTS3 (MW389059), Corynebacterium sp. CTS5 (MW389060), Providencia sp. CTS12 (MW389066), and Pseudomonas sp. CTS17 (MW389070). In addition, the major bacterial strains have been deposited into the public BCCM/LMG Bacteria Collection with the accession numbers: Acinetobacter sp. CTS3 (LMG 32,410), Corynebacterium sp. CTS5 (LMG 32,411), Providencia sp. CTS12 (LMG 32,412), and Pseudomonas sp. CTS17 (LMG 32,413).

\section{Declarations}

Ethics approval and consent to participate

This article does not contain any studies with human participants or animals performed by any of the authors.

\section{Consent for publication}

Not applicable.

\section{Competing interests}

The authors declare that the research was conducted in the absence of any commercial or financial relationships that could be construed as a potential conflict of interest.

\section{Author details}

1 TERRA Research and Teaching Centre, Microbial Processes and Interactions (MiPI), Gembloux Agro-Bio Tech, University of Liège, 5030 Gembloux, Belgium. ${ }^{2}$ School of Food and Pharmaceutical engineering, Nanjing Normal University, 210000 Nanjing, China.

Received: 2 December 2021 Accepted: 12 February 2022 Published online: 04 March 2022

\section{References}

Abo-Amer AE, Ramadan AB, Abo-State M, Abu-Gharbia MA, Ahmed HE (2013) Biosorption of aluminum, cobalt, and copper ions by Providencia rettgeri isolated from wastewater. J Basic Microbiol 53(6):477-488

Anandkumar B, George R, Philip J (2020) Efficacy of imidazolium and piperidinium based ionic liquids on inhibiting biofilm formation on titanium and carbon steel surfaces. Anal Chim Acta 1126:38-51

Antoniani D, Bocci P, Maciąg A, Raffaelli N, Landini P (2010) Monitoring of diguanylate cyclase activity and of cyclic-di-GMP biosynthesis by wholecell assays suitable for high-throughput screening of biofilm inhibitors. Appl Microbiol Biotechnol 85(4):1095-1104

Armbruster CR, Parsek MR (2018) New insight into the early stages of biofilm formation. Proc Natl Acad Sci 115(17):4317-4319

Bott T (1998) Techniques for reducing the amount of biocide necessary to counteract the effects of biofilm growth in cooling water systems. Appl Therm Eng 18(11):1059-1066

Brathwaite CW, Dickey RS (1970) Synergism between Pseudomonas caryophylli and a species of Corynebacterium. Phytopathology 60(7):1046-1051

Ceyhan N, Ozdemir G (2008) Extracellular polysaccharides produced by cooling water tower biofilm bacteria and their possible degradation. Biofouling 24(2):129-135 
Cho KH, Tryon RG, Kim J-H (2020) Screening for diguanylate cyclase (DGC) inhibitors mitigating bacterial biofilm formation. Front Chem 8:264

Darabedian N, Chen TC, Molina H, Pratt MR, Schönthal AH (2018) Bioorthogonal profiling of a cancer cell proteome identifies a large set of 3-bromopyruvate targets beyond glycolysis. ACS Chem Biol 13(11):3054-3058

Di Gregorio L, Tandoi V, Congestri R, Rossetti S, Di Pippo F (2017) Unravelling the core microbiome of biofilms in cooling tower systems. Biofouling 33(10):793-806

Di Pippo F, Di Gregorio L, Congestri R, Tandoi V, Rossetti S (2018) Biofilm growth and control in cooling water industrial systems. FEMS Microbiol Ecol 94(5):fiy044

Doğruöz N, Göksay D, Ilhan-Sungur E, Cotuk A (2009) Pioneer colonizer microorganisms in biofilm formation on galvanized steel in a simulated recirculating cooling-water system. J Basic Microbiol 49(S1):S5-S12

Edagawa A, Kimura A, Doi H, Tanaka H, Tomioka K, Sakabe K, Nakajima C, Suzuki Y (2008) Detection of culturable and nonculturable Legionella species from hot water systems of public buildings in Japan. J Appl Microbiol 105(6):2104-2114

Elias S, Banin E (2012) Multi-species biofilms: living with friendly neighbors. FEMS Microbiol Rev 36(5):990-1004

Flemming H-C (2020) Biofouling and me: My Stockholm syndrome with biofilms. Water Res 173:115576

Flemming H-C, Wingender J, Szewzyk U, Steinberg P, Rice SA, Kjelleberg S (2016) Biofilms: an emergent form of bacterial life. Nat Rev Microbiol 14(9):563

Fux CA, Costerton JW, Stewart PS, Stoodley P (2005) Survival strategies of infectious biofilms. Trends Microbiol 13(1):34-40

Greay TL, Gofton AW, Zahedi A, Paparini A, Linge KL, Joll CA, Ryan UM (2019) Evaluation of 165 next-generation sequencing of hypervariable region 4 in wastewater samples: an unsuitable approach for bacterial enteric pathogen identification. Sci Total Environ 670:1111-1124

Han Y, Yang T, Xu G, Li L, Liu J (2020) Characteristics and interactions of bioaerosol microorganisms from wastewater treatment plants. J Hazard Mater 391:122256

Hansen SK, Rainey PB, Haagensen JA, Molin S (2007) Evolution of species interactions in a biofilm community. Nature 445(7127):533-536

Harrison JJ, Ceri H, Turner RJ (2007) Multimetal resistance and tolerance in microbial biofilms. Nat Rev Microbiol 5(12):928-938

Jenal U, Reinders A, Lori C (2017) Cyclic di-GMP: second messenger extraordinaire. Nat Rev Microbiol 15(5):271-284

Jo SJ, Kwon H, Jeong S-Y, Lee SH, Oh H-S, YiT, Lee C-H, Kim TG (2016) Effects of quorum quenching on the microbial community of biofilm in an anoxic/oxic MBR for wastewater treatment. J Microbiol Biotechnol 26(9):1593-1604

Karygianni L, Ren Z, Koo H, Thurnheer T (2020) Biofilm Matrixome: Extracellular Components in Structured Microbial Communities. Trends Microbiol 28(8):668-681

Kumar S, Stecher G, Li M, Knyaz C, Tamura K (2018) MEGA X: molecular evolutionary genetics analysis across computing platforms. Mol Biol Evol 35(6):1547-1549

Kwak J, Yoon S, Mahanty B, Kim C-G (2017) Redox-mediator-free degradation of sulfathiazole and tetracycline using Phanerochaete chrysosporium. J Environ Sci Health A 52(13):1211-1217

Li H, Chien S-H, Hsieh M-K, Dzombak DA, Vidic RD (2011) Escalating water demand for energy production and the potential for use of treated municipal wastewater. Environ Sci Technol 45(10):4195-4200

Liu W, Jacquiod S, Brejnrod A, Russel J, Burmølle M, Sørensen SJ (2019) Deciphering links between bacterial interactions and spatial organization in multispecies biofilms. ISME J 13(12):3054-3066

Lohse MB, Gulati M, Craik CS, Johnson AD, Nobile CJ (2020) Combination of antifungal drugs and protease inhibitors prevent Candida albicans biofilm formation and disrupt mature biofilms. Front Microbiol 11:1027

MacDonald R, Brözel V (2000) Community analysis of bacterial biofilms in a simulated recirculating cooling-water system by fluorescent in situ hybridization with rRNA-targeted oligonucleotide probes. Water Res 34(9):2439-2446

Mohiuddin SG, Hoang T, Saba A, Karki P, Orman MA (2020) Identifying Metabolic Inhibitors to Reduce Bacterial Persistence. Front Microbiol 11:472
Moynihan MM, Murkin AS (2014) Cysteine is the general base that serves in catalysis by isocitrate lyase and in mechanism-based inhibition by 3-nitropropionate. Biochemistry 53(1):178-187

Ogawa A, Kanematsu H, Sano K, Sakai Y, Ishida K, Beech IB, Suzuki O, Tanaka T (2016) Effect of silver or copper nanoparticles-dispersed silane coatings on biofilm formation in cooling water systems. Materials 9(8):632

Paranjape K, Bédard É, Whyte LG, Ronholm J, Prévost M, Faucher SP (2020) Presence of Legionella spp. in cooling towers: the role of microbial diversity, Pseudomonas, and continuous chlorine application. Water Res 169:115252

Parijs I, Steenackers HP (2018) Competitive inter-species interactions underlie the increased antimicrobial tolerance in multispecies brewery biofilms. ISME J 12(8):2061-2075

Peer R, Sanders TK (2016) Characterizing cooling water source and usage patterns across US thermoelectric power plants: a comprehensive assessment of self-reported cooling water data. Environ Res Lett. 11:12

Pereira RP, Peplies J, Höfle MG, Brettar I (2017) Bacterial community dynamics in a cooling tower with emphasis on pathogenic bacteria and Legionella species using universal and genus-specific deep sequencing. Water Res 122:363-376

Pereira R, Peplies J, Mushi D, Brettar I, Höfle MG (2018) Pseudomonasspecific NGS assay provides insight into abundance and dynamics of Pseudomonas species including P. aeruginosa in a cooling tower. Front Microbiol 9:1958

Pinel IS, Kim LH, Proença Borges VR, Farhat NM, Witkamp G-J, van Loosdrecht MC, Vrouwenvelder JS (2020) Effect of phosphate availability on biofilm formation in cooling towers. Biofouling 36(7):800-815

Pinhal S, Ropers D, Geiselmann J, de Jong H (2019) Acetate metabolism and the inhibition of bacterial growth by acetate. J Bacteriol Res. 201:13

Qvortrup K, Hultqvist L, Nilsson M, Jakobsen TH, Jansen CU, Uhd J, Andersen JB, Nielsen TE, Givskov M, Tolker-Nielsen T (2019) Small molecule antibiofilm agents developed on the basis of mechanistic understanding of biofilm formation. Front Chem 7:742

Rabin N, Zheng Y, Opoku-Temeng C, Du Y, Bonsu E, Sintim HO (2015) Biofilm formation mechanisms and targets for developing antibiofilm agents. Future Med Chem 7(4):493-512

Reddy GKK, Nancharaiah Y, Venugopalan V (2017) Long alkyl-chain imidazolium ionic liquids: Antibiofilm activity against phototrophic biofilms. Colloids Surf B 155:487-496

Ren D, Madsen JS, de la Cruz-Perera Cl, Bergmark L, Sørensen SJ, Burmølle M (2014) High-throughput screening of multispecies biofilm formation and quantitative PCR-based assessment of individual species proportions, useful for exploring interspecific bacterial interactions. Microb Ecol 68(1):146-154

Ren D, Madsen JS, Sørensen SJ, Burmølle M (2015) High prevalence of biofilm synergy among bacterial soil isolates in cocultures indicates bacterial interspecific cooperation. ISME J 9(1):81-89

Røder HL, Sørensen SJ, Burmølle M (2016) Studying bacterial multispecies biofilms: where to start? Trends Microbiol 24(6):503-513

Rodríguez-Calvo A, Gonzalez-Lopez J, Ruiz LM, Gómez-Nieto M, Muñoz-Palazon B (2020) Effect of ultrasonic frequency on the bacterial community structure during biofouling formation in microfiltration membrane bioreactors for wastewater treatment. Int Biodeterior Biodegradation 155:105102

Saiardi A, Azevedo C, Desfougères Y, Portela-Torres P, Wilson MS (2018) Microbial inositol polyphosphate metabolic pathway as drug development target. Adv Biol Regul 67:74-83

Sharma V, Sharma S, Zu Bentrup KH, McKinney JD, Russell DG, Jacobs WR, Sacchettini JC (2000) Structure of isocitrate lyase, a persistence factor of Mycobacterium tuberculosis. Nat Struct Biol 7(8):663-668

Sharmin F, Wakelin S, Huygens F, Hargreaves M (2013) Firmicutes dominate the bacterial taxa within sugar-cane processing plants. Sci Rep 3:3107

Tan CH, Lee KWK, Burmølle M, Kjelleberg S, Rice SA (2017) All together now: experimental multispecies biofilm model systems. Environ Microbiol 19(1):42-53

Tsao H-F, Scheikl U, Herbold C, Indra A, Walochnik J, Horn M (2019) The cooling tower water microbiota: Seasonal dynamics and co-occurrence of bacterial and protist phylotypes. Water Res 159:464-479 
Valentini M, Filloux A (2016) Biofilms and cyclic di-GMP (c-di-GMP) signaling: lessons from Pseudomonas aeruginosa and other bacteria. J Biol Chem 291(24):12547-12555

Wilbanks B, Trinh CT (2017) Comprehensive characterization of toxicity of fermentative metabolites on microbial growth. Biotechnol Biofuels 10(1):1-11

Xiao Y, Liu Y, Ma C, Muhammad T, Zhou B, Zhou Y, Song P, Li Y (2020) Using electromagnetic fields to inhibit biofouling and scaling in biogas slurry drip irrigation emitters. J Hazard Mater 401:123265

Yu W, Hallinen KM, Wood KB (2018) Interplay between antibiotic efficacy and drug-induced lysis underlies enhanced biofilm formation at subinhibitory drug concentrations. Antimicrob Agents Chemother. 62:1

Zhou M, Yan B, Wong JW, Zhang Y (2018) Enhanced volatile fatty acids production from anaerobic fermentation of food waste: a mini-review focusing on acidogenic metabolic pathways. Bioresour Technol 248:68-78

\section{Publisher's Note}

Springer Nature remains neutral with regard to jurisdictional claims in published maps and institutional affiliations.

\section{Submit your manuscript to a SpringerOpen ${ }^{\odot}$ journal and benefit from:}

- Convenient online submission

- Rigorous peer review

- Open access: articles freely available online

- High visibility within the field

- Retaining the copyright to your article

Submit your next manuscript at $\boldsymbol{\nabla}$ springeropen.com 